\title{
Imagined lives
}

$\mathrm{M}$ any historic photographic portraits have endured, but more often than not the narrative account of the portrayed person has been lost. John Wood, an award-winning poet and photographic historian, has melded 19th century photographs by O.G. Mason with case studies from pioneering dermatologist Dr. George Henry Fox and reimagined the portrayed patient's life in poetry. In his exquisitely produced book, Endurance and Suffering: Narratives of Disease in the 19th Century (Galerie Vevais, Germany; 2008), Wood fosters an intimate imaginative relationship with the subjects of the photographs.
"I wanted to take these clinical photographs and case studies and infuse them with the humanity the lives of these people deserved," says Wood. "None of them could have had easy lives - especially the poor lady who had lost her nose to syphilis. What could such a fate have been like? I wanted to know how she lived it, how she endured it. She was a wife, a mother. Like many women, she contracted it from her husband, who then deserted her." Fox made a point of reminding people that "Syphilis is by no means a disease which invariably acknowledges a venereal origin" and spoke of the scores of lives tragically scarred by it "of which no record is made, no history written." Wood wanted to write this woman's history. "We look at her face and at first might want to turn away, but after looking at her and thinking about her for a long time, I could begin to imagine her days and their terrible routine, how she was condemned to live, like Tennyson's Tithonus, as 'a shadow roaming like a dream." - Barbara Sibbald, CMAJ

More book excerpts are available at: www.cmaj.ca/cgi/content/full/180/1/80/DC1

\section{Syphiloderma Tuberculosum: Lady in a hat}

The crescentic and circular arrangement of the lesions left no doubt as to the nature of the affection. There is scarcely a more unmistakable eruption figured in the whole series.

Well, then, you can just kiss my arse;

I'm not taking the hat off. A lady without a hat is no lady. I'm not one of your old whores here to have her ailing privates looked at.

I assume you're familiar with quality: note the eardrops, real jet, worth tidy sums. Like my bonnet, they come from Paree. And this is pure Belgium lace on my bosoms.

I have several French admirers. I talk French to them... at the opera... drinking mugs of champagne. They buy me furs and whole hams and look at me and just ooh and ah.

I'm only here to visit Dr. Fox

and get another dose of mercury. It's more like a rash than the pox, and I really don't give a damn about photography.

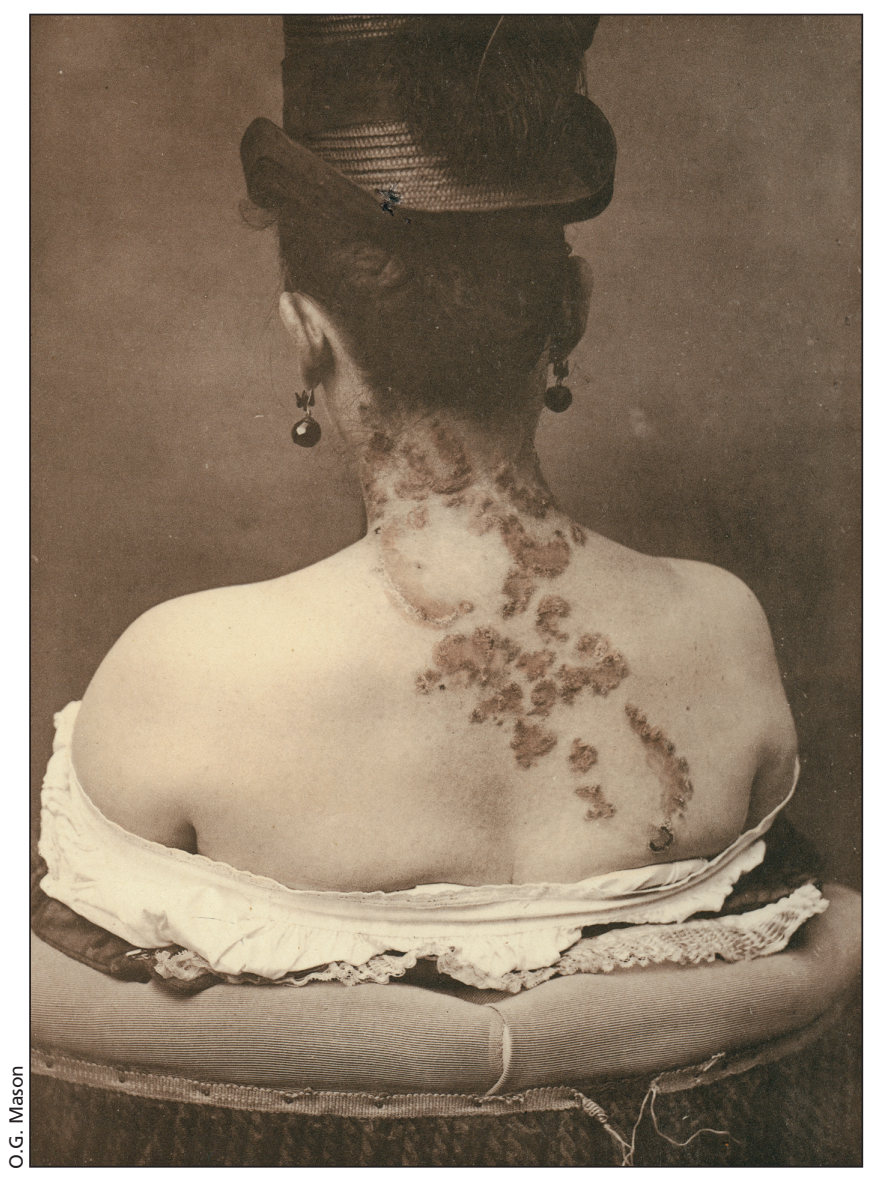




\section{Syphiloderma Ulcerativum Perforans}

Overwhelmed by her days, her neighbors' talk and her son's shame, she goes about her house as she has always done, doing the things that she has always done - the usual things women do: turning melon rinds and plums into preserves, canning peppers and peas, and hanging laundry on the lines, dusting, and in the evening sitting down to read, often on the porch when the weather was porch-weather and the light lingered longer. Her son seldom writes anymore, but knows that she must have gotten it from Papa, who left last year, saying her "cold, bleak ways" had burst his heart. Of course, that wasn't it, but she knew nothing of other women. And so sadness tumbled into her eyes, balked and stranded there. The headaches began, then ulcerations, the decay. Her lips pulled down with the weight of her thought. She quit the church: too many whispers and too quick the silence when she entered any room; no one could talk to her without staring into the center of her face. And some would even ask, "Oh, Mrs. So and So, have you heard from that nice husband of yours lately? He's still on that job; where was it? Ohio? And such a good man. Pity he hasn't come home yet." Blame everywhere. And nothing she could say to anyone. She's kept his picture, a rose he gave her she pressed into a book of Tennyson's, a closet of his clothes and pairs of shoes. She recalls what she thought were glittering days: a son in her arms, a husband smiling, the talk of all they would do together, all the yesterdays they swore would sustain every tomorrow through the calendars' slow, relentless erosion of the world. Now, here at its quiet limits, she withers slowly, a shadow roaming like a dream.

\section{C.R., age 20, U.S.: acne}

The patient was of fair complexion, with a naturally delicate skin. A marked flushing of the face ensued upon mental excitement or slight external irritation.

If you would understand this classic face, forget youth's clumsy angers, its acne and fears. Then you will see the sculpted grace of ancient days, austere in its beauty.

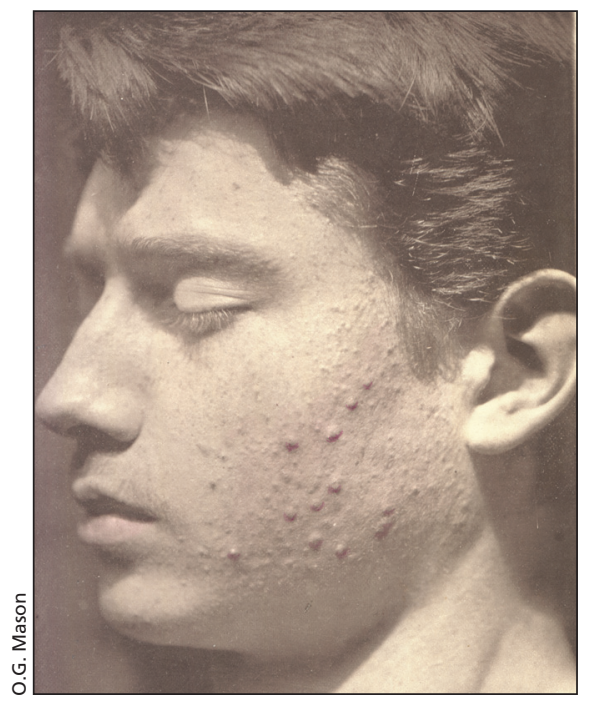




\section{Ellen Collins, age 37: skin graft}

Ellen Collins was admitted to Bellevue Hospital, October 1871, for a burn from kerosene oil. After 5 months' treatment the wound assumed the appearance seen in the illustration. On March 10, 1872, I immersed an amputated leg in hot water and began grafting from it. Thirty grafts were applied on the right side and covering a vertical space five by four and a-half inches, and almost all succeeded. March 23. Being unable to take the amputated limb immediately to my patient, I wrapped it in flannel and placed it behind a coil of steam pipes; beginning grafting one hour and thirty-five minutes after the operation. About one hundred grafts were applied, eighty-nine successful ones. An acute pleurisy then set in and caused her death on June 22, when everything promised success. She had received in all over 1500 grafts in less than a year. (The preceding is abridged from a text by the patient's doctor, Geo. A. Van Wagenen MD, the former house surgeon at Bellevue Hospital, New York City, New York).

I tried to rhyme her breasts with bits of skin and patch her broken meters back to song. But pain stitched on and on. No art that l'd enjoin could lyric back her breasts from fire or mend such loss_-or make her husband kind:

he'd "never love a chest of scars." So I was left to wooing with scalpels and grafts, salves and sutures, and the legs l'd warmed from cadavers. Soon I'd learned her body like a lover.

But after the months of grafting, so much intimacy without romance, her life blistered with grief and grievance. She'd take no more of my artless crafting, and all my love and all my skill flamed to nothing.

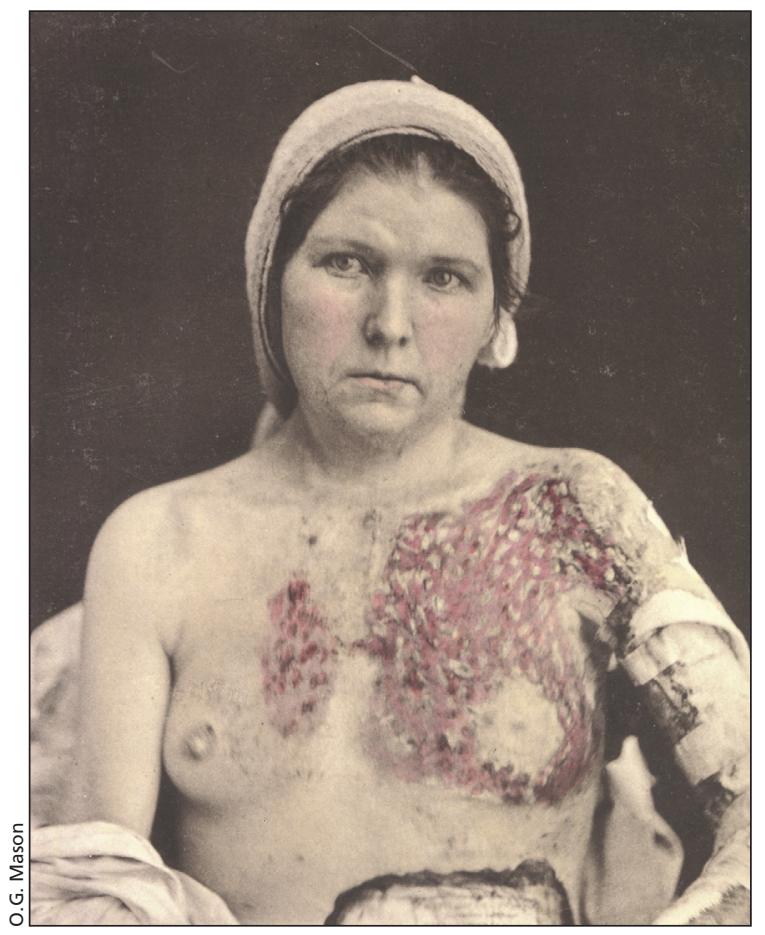

John Wood MFA PhD

Poet and photographic historian

Saxtons River, Vermont

John Wood is the award-winning author of 4 books of poetry and 4 critical books on the photographic arts. He has also co-curated a photo exhibition at the Smithsonian Institution and edited more than 25 books. He is currently editing The Journal of Joel-Peter Witkin (21st Editions). Endurance and Suffering won the 2009 Deutscher Fotobuchpreis Gold Medal.

Endurance and Suffering is available in North America at www.photoeye.com and in Europe at http://anamorfose.be/

\section{A note from the Humanities' editor}

Y ou may have noticed that The Left Atrium has morphed, in this issue, into Humanities. The change in name highlights systemic changes throughout the section that are designed to make it a more accessible and pertinent source of inspiration, reflection and insight for physicians.

The 7 departments within the section have been synthesized into Reviews, Creative Works and Essays. The section will be rooted in Reviews, primarily of books, but also new media and art (in all its delightful permutations). The Creative
Works department will showcase original works of art, including poetry, short fiction, narrative medicine accounts, fine art and photography. Essays will explore a range of subjects, such as history, anthropology, ethics, culture and sociology, and will include profiles of inspiring people.

Other changes to the print and online humanities section will be introduced throughout 2009.

The Left Atrium was launched in January 1999 with the stated purpose of conveying "the art and humanities aspects of medicine to our readers and, in particular, providing sustenance for the practice of this art through contemplation." A decade later that commitment remains unchanged.

I would like to thank everyone who participated in the brainstorming sessions that led to these changes. I welcome your comments as well as your submissions for possible publication (for details see www.cmaj.ca/authors/preparing.shtml).

\section{Barbara Sibbald BJ}

Deputy Editor, News and Humanities CMAJ 